\title{
A Study on the Student Drain of the Major of Automobile Service Engineering
}

\author{
Zhuo Yang \\ Faculty of Mechanical Engineering \\ Zhuhai College of Jilin University \\ Zhuhai, China \\ 641610495@qq.com \\ Shaojia Huang \\ Faculty of Mechanical Engineering \\ Zhuhai College of Jilin University \\ Zhuhai, China
}

\author{
Yanbo Deng \\ Faculty of Electrical Engineering \\ Zhuhai College of Jilin University \\ Zhuhai, China
}

\author{
Xiqing Wang \\ Faculty of Mechanical Engineering \\ Zhuhai College of Jilin University \\ Zhuhai, China
}

\author{
Mingchen Shi \\ Faculty of Mechanical Engineering \\ Zhuhai College of Jilin University \\ Zhuhai, China
}

\begin{abstract}
With the growing of the sale and the car ownership in China, the automotive after-market is full of business opportunities which induce the short supply of talent for the automobile service engineering. Therefore, since the automobile service engineering was approved as a specialty for higher education by the Ministry of Education of the People's Republic of China in 2003, more than 163 colleges and universities in China set up such a specialty. However, although the employment prospect of this specialty is bright, the number of the students for this major is small which is characterized as the less enrollment and the switching to another major after a period of study on automobile service engineering. The innovation of this paper lies in that we investigated such a phenomenon by questionnaires in Zhuhai College of Jilin University and we find that the reason lies in both students and the publicity of the major.
\end{abstract}

Keywords-automotive; after-market; automobile service engineering; switch of major

\section{INTRODUCTION}

By the end of 2015, the possession of the civil vehicle in China reached more than 160 million [1], and it is estimated that in 2020, China civilian car ownership will reach 250 million [2]. In addition, the yields and the sales of the vehicle in China, as well as their growth rates, increased gradually from 2012 to 2016 (Fig. 1). Therefore, with the booming of the car ownership in China, it is believed that the automotive after-market service revenue is expected to reach 45 per cent/55 per cent of the total auto industry value chain's revenue by $2020 / 2025$ [3].

The number of the graduates whose major is automobile service engineering ranges from 5000 to 6000 for each year, and the rate of the employment were as higher as $80 \%$ in the

This work is supported by the "Three levels of talent construction project of Zhuhai College of Jilin University. last three years [4]. In the view of employment, students have a variety of options for the career which ranges from auto parts industry to electronic commerce. In a recent investigation in 2017 (Fig. 2), about 35\% graduates choose the auto and auto part industry after graduation while $7 \%$ graduates dedicate to computer industry [5]. In addition, students who graduated from automobile service engineering choose to start their career in the first-tier and second-tier cities where there is a substantial demand for automotive after-market service. For example, as is shown in Fig. 3, the demand for graduates who graduated from automobile service engineering accounted for 30\% in Shanghai in 2017.

\section{CASE STUDY}

Although the auto industry is a growth industry in recent years in China [6] and the career prospect of the automotive service engineering is bright, the enrollment for this major has been decreasing from the year 2009 in Zhuhai College of Jilin University. In addition, some students would transfer to other specialties after one-year study in this major. The diminishing enrollment influence the arrangement of the curriculum as well as the teaching of the courses in this major. Fig. 4 shows the decreasing trend of the enrollment of the automotive service engineering from 2008 to 2017 in Zhuhai College of Jilin University. The mean of the number of the enrollment in the 12 years was only 78, and the trend of the number of the enrollment was decreasing although there are two peaks in $2008(\mathrm{n}=121)$ and $2015(\mathrm{n}=90)$. In addition, from 2014 to 2016, there were 85 students switched to other majors from automotive service engineering (Fig. 5). As we can see, the numbers of students who switched to finance and accounting were as many as 20 and 13, respectively. And there were 8 students switched to automotive engineering which emphasized on the theory, design and manufacturing of an automobile. 
Therefore, we investigated this phenomenon by questionnaire in Zhuhai College of Jilin University. We distributed the questionnaire to 44 interviewees who switched to other departments and 30 of which were male. The interviewees were from different grades. The numbers of the interviewees from grade 2014, 2015 and 2016 were 10, 16 and 18, respectively. The questionnaire consists of ten questions which focus on the cognition of the automobile service engineering and the learning situation in current major.
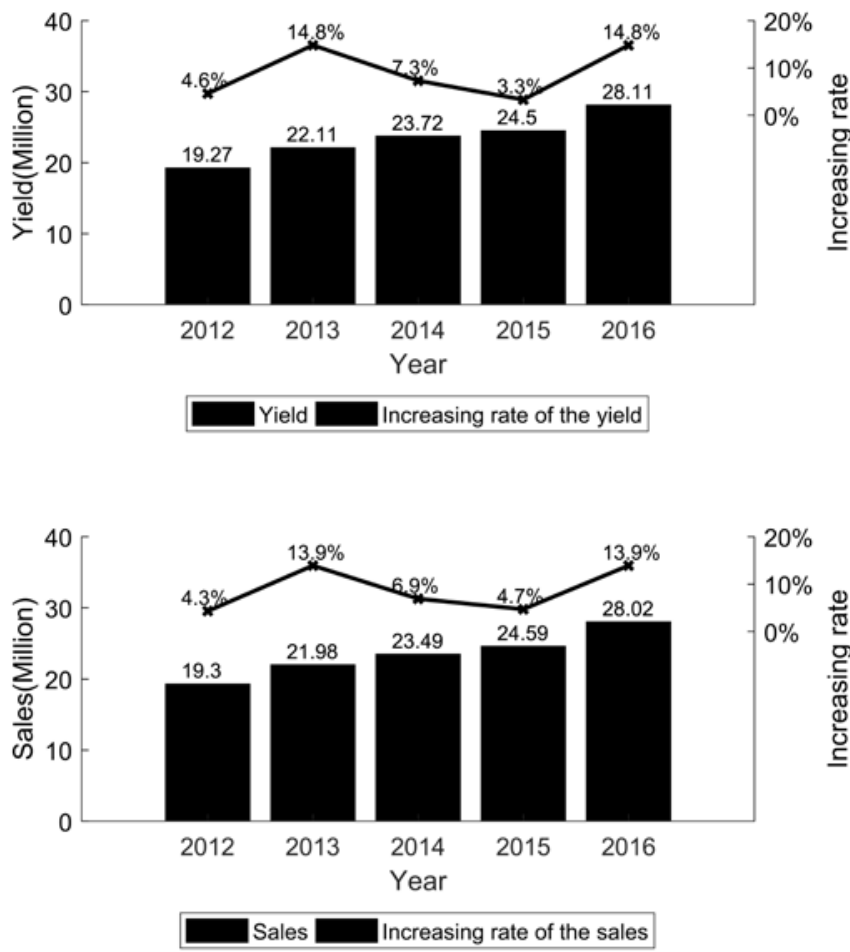

Fig. 1. The yields and the sales of the vehicle in China as well as their growth rates from 2012 to 2016.

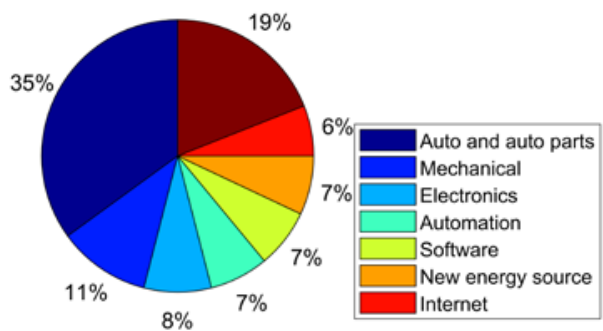

Fig. 2. The distribution of employ ment for automobile service engineering in 2017

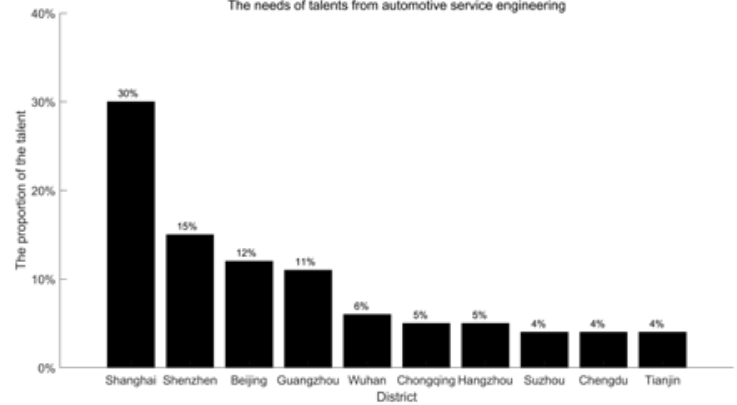

Fig. 3. The comparison of the demand for the talent graduated from automotive service engineering.

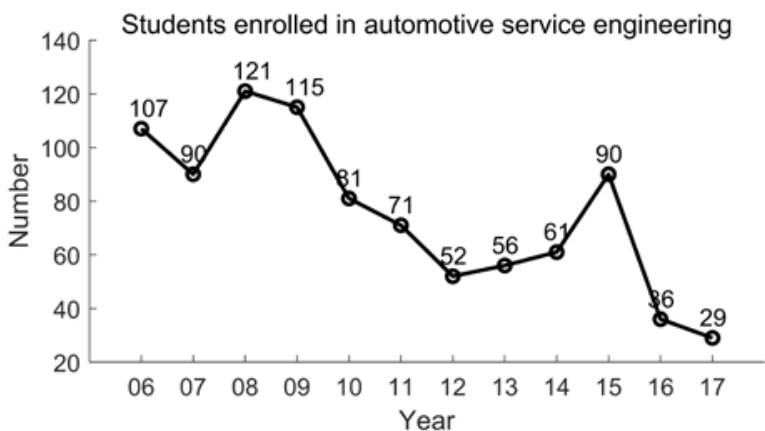

Fig. 4. The number of the enrollment in the automobile service engineering in Zhuhai College of Jilin University from 2006 to 2017

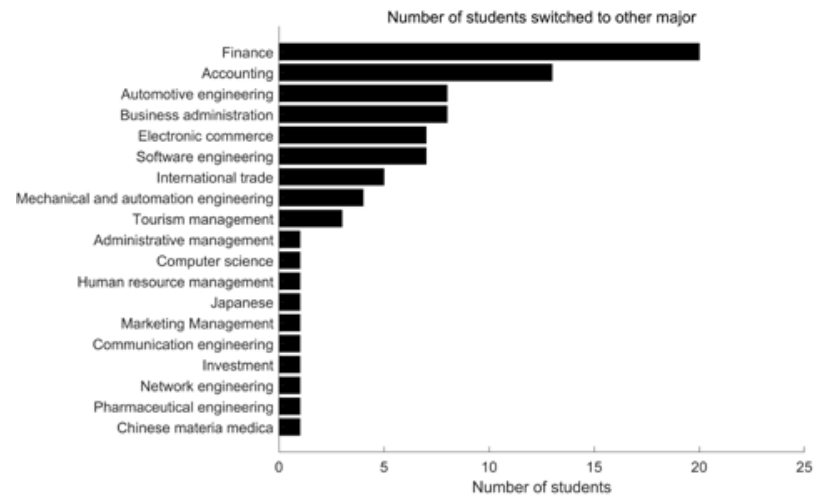

Fig. 5. The number of students switched to other major from automobile service engineering in 2014, 2015 and 2016.

1. Why did you choose this major before switching to another major?

A: Hobby; B: Career prospect; C: Higher acceptance rate; D: Subject to professional adjustment; E: Adopt parents'advice

2. Do you know the difference between research-oriented university and the application-oriented university?

A: Yes; B: No;

3. Do you like this automobile service engineering?

A: Yes; B: No; C: Not clear about the major

4. What do you think about the career prospect of this major?

A: Good; B: So-so; C: Bad

5. What kind of work do you think you will be engaged in after graduation from auto mobile service engineering (both before and after switching to another major)?

6. When did you decide to switch to other major?

A: Receiving the admission letter; B: After a period of study; C: A sudden decision; D: After one-year study; E: Others

7. Compared with automobile service engineering, what about the 
specialty courses in other majors?

A: OK, match my expectation; B: Profound and lack of practice; C: Tedious; D: Lack of something interesting especially in experimental courses; D: Dislike it

8. Are you satisfied with your new major and what about your learning attitude?

A: It is OK; B: It is great; C: So-so; D: Not so satisfied; E: Regret

9. What do you think about the specialty courses of automobile service engineering?

A: Not interested; B: It won't be a benefit to the career; C: The depth of knowledge is not adequate; D: Unsatisfied with the environment for study; E: Too complex to understand

10. Why did you switch to another major after a period of study?

A: Not interested; B: Feel difficult in courses; C: Bad career prospect; D: Hope to switch to another major by professional adjustment at the very beginning; E: Parents' suggestions; F: Conformity psychology; G: The name of major is not so professional; $\mathrm{H}$ : Bad interpersonal communication; I: Others

The statistical information of the questionnaire is shown below. Fig. 6 shows the distribution of students who chose automobile service engineering before switching to another major. From this figure, we find that $33.3 \%$ students were subject to the profession adjustment while only 15\% students believed that the career prospect is bright for this major. At the same time, 55\% students were not familiar with this major, and only $27 \%$ student liked this major before the enrollment (question 3). The property of the university (research-oriented or application-oriented) manifests the cultivation mode of the student as well as the career after graduation. And the automobile service engineering is a major which focus on cultivating application-oriented talent. However, about 34\% students, a large proportion, do not know such a difference (question 2). Question 4 is related to the extent of the awareness of the career prospect after graduation. Less than half students (46\%) believed that they would have a bright future if they engaged in this service. Fig. 7 shows the comparison of the cognition of the career before and after switching to another major (question 5). After a period of study on this major, less individual believed that their job would be related to the car washing and more individual got aware that they could engage in the automotive press. As is shown in Fig. 8 , about $34 \%$ students decided to switch to another major once receiving the letter of admission which manifested that this major was always a stepping stone to other majors (question 6). Fig. 9 shows the satisfaction and the learning attitude towards the new major (question 7 and question 8). Only 50\% students were satisfied with the new major, and only 34\% students are enthusiastic about their new majors. Another important reason for the major switching lies in the difficulty of the specialty courses of the automobile service engineering (question 9). More than half of the students (59\%) suggested that the specialty courses were too complex to understand (Fig. 10). And the last question which is related to the reasons for switching major also manifests that the specialty courses of the automobile service engineering are difficult for these students (27\% students). In addition, lacking of interest (34\% students) in such a major is the most important reason for switching major (Fig. 11).

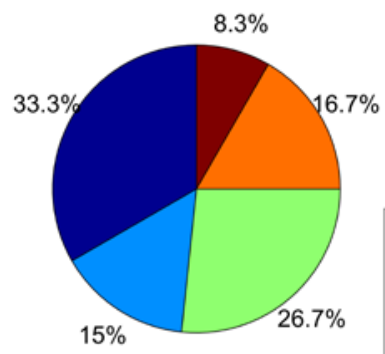

Subject to professional adjustment Adopt parents' advice Hobby

Career prospect

Higher acceptance rate

Fig. 6. The distribution for the reason of choosing automobile service engineering before switching to another major

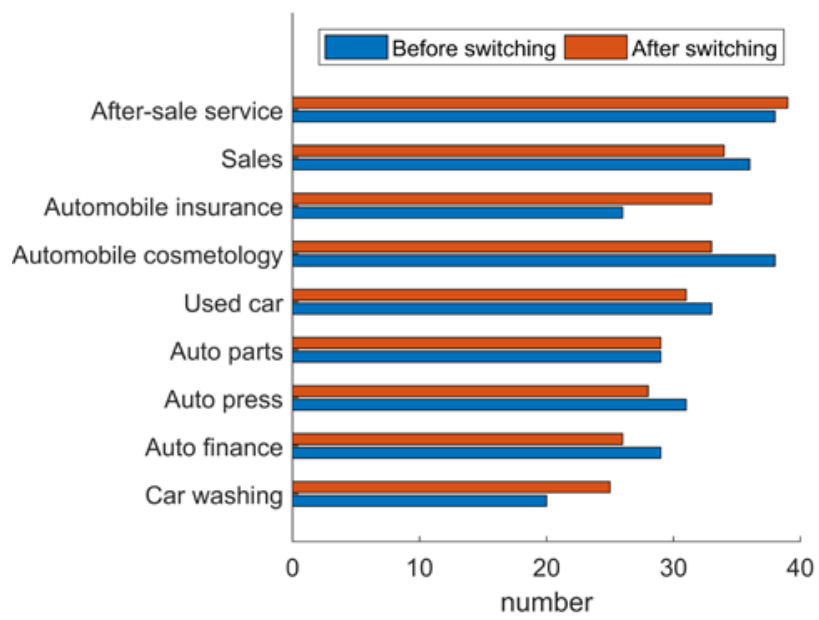

Fig. 7. The comparison of the cognition of the career before and after switching to another major

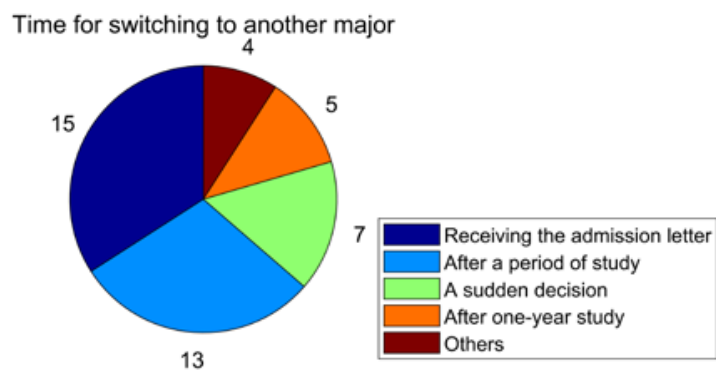

Fig. 8. The distribution of the time of switching to another major 

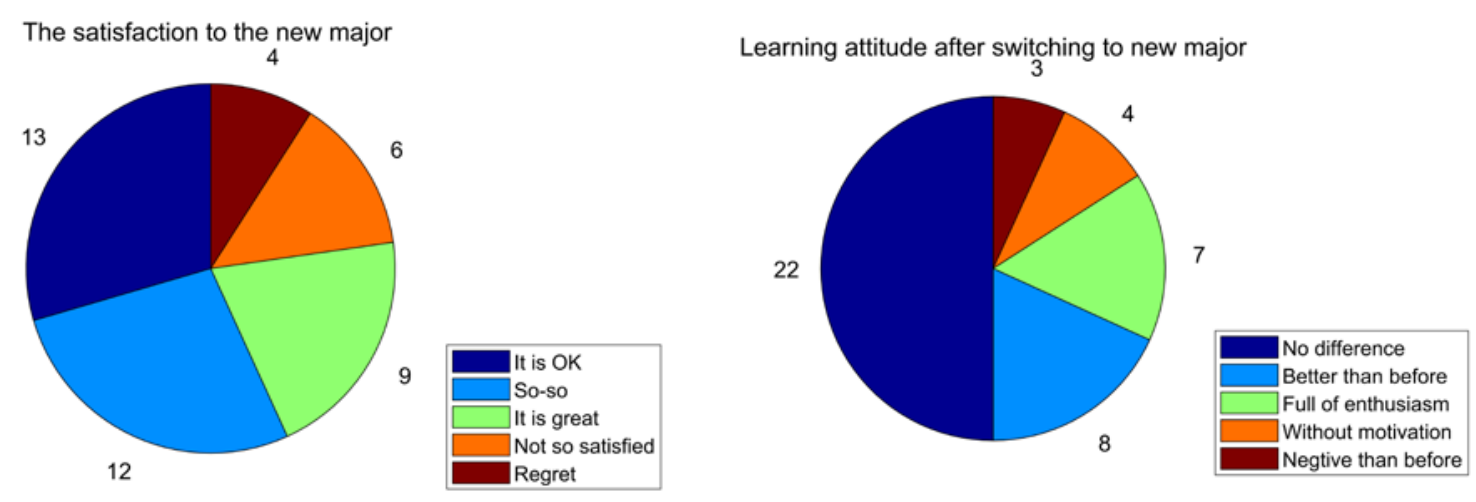

Fig. 9. The satisfaction and the learning attitude towards the new major

The recognition of the specialty courses of automobile service engineering

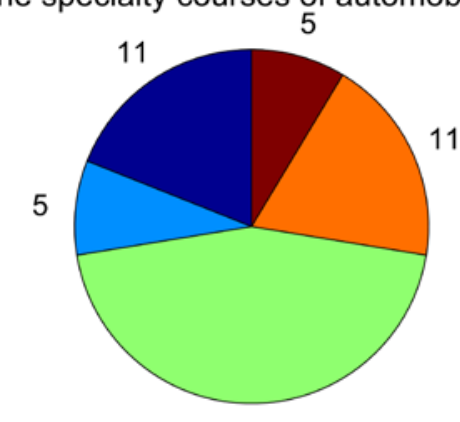

26

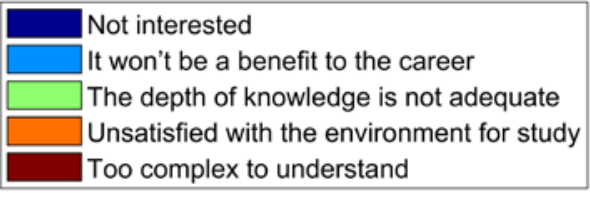

Fig. 10. The recognition to the specialty courses of the automobile service engineering

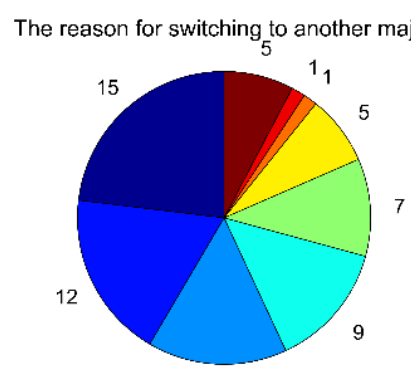

10

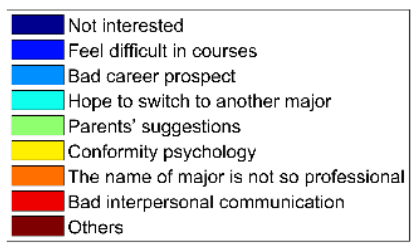

Fig. 11. The distribution of the reasons for switching major

\section{CONCLUSION}

This paper investigated the reasons for the loss of students in automobile service engineering although the career prospect is bright. We distributed a questionnaire to 44 students who had switched to another major. We find that the lose of the students lies in both the factor of the student himself and the publicity of the major. In addition, the tutor should combine the theory and practice to make it a more attractive course.

\section{REFERENCE}

[1] "Possession of Civil Vehicle," 2016. Available: http://www.stats.gov.cn/tjsj/ndsj/2016/indexeh.htm (In Chinese)

[2] N. Wang, H. Pan, and W. Zheng, "Assessment of the incentives on electric vehicle promotion in China,” Transport Res A-Pol, vol. 101, pp. 177-189, 2017.

[3] “Automotive to China," $2017 . \quad$ Available: www.austrade.gov.au/australian/export/export-markets/countries/china/in dustries/Automotive(In Chinese)

[4] Available: http://gaokao.chsi.com.cn/gkxx/zybk/zt/201612/20161216/1574082480.ht ml (In Chinese)

[5] J. Feng, "The analysis of career prospects for automobile service engineering in 2017.” 2017. Available: http://www.gaosan.com/gaokao/96860.html (In Chinese)

[6] P. Gao, R. Hensley, and A. Zielke, "A road map to the future for the auto industry,” McKinsey Quarterly, October, 2014. 